\title{
Characteristics of multi drug resistant tuberculosis cases at a selected tertiary level hospital
}

\author{
Mahbubul Hoque AK ${ }^{1}$, Rahman $M^{2}$, Saleh Bhuiyan S.M.M ${ }^{3}$, Rahman $M^{4}$ \\ Colonel (Dr) A K Mahbubul Hoque, ${ }^{2}$ Prof (Dr) Mahfuzar Rahman, ${ }^{3}$ Brigadier General (Dr) S.M.M. Saleh Bhuiyan, \\ ${ }^{4}$ Colonel (Dr) MD Mahbubur Rahman Retd,
}

Address for Correspondence: Colonel (Dr) A.K. Mahbubul Hoque, MPH, MPhil, Specialist in Health Care and Hospital Management, Assistant Director Medical Services (ADMS), 17 Infantry Division, Jalalabad Cantonment, Sylhet. Bangladesh.

\begin{abstract}
Background: This study was carried out to determine the characteristics of MDR-TB cases under treatment at National Institute of Diseases of the Chest and Hospital (NIDCH), Mohakhali, Dhaka. Methods: This was a descriptive cross sectional study among 442 diagnosed MDR-TB patients admitted in NIDCH of which 303 MDR-TB patients were included as respondents. The respondents were selected purposively and they were interviewed with duly pre-tested research instruments. Results: Among the study populations (303), all were resistant to H \& R and 149 (57.7\%) consumed standard drugs regimen contained H, R, E \& S. In addition the factors related to develop MDR-TB mostly as non-compliance, overcrowding and exposure to MDR-TB were 190 (73.7\%), $261(86.1 \%)$ and 81 (26,7\%) respectively. In this study, time interval between completed anti-TB treatment and diagnosis of MDR-TB found 01 to 06 years among $55.4 \%$ respondents. Moreover tools used for diagnosis of MDR-TB were found in $258(85.1 \%)$ as smear for AFB, Gene expert tests and Culture. Age group 16 to 30 yrs $184(60.7 \%)$, income group 10001 to 20000 taka per month 143 (47.2\%), educational qualification class VI-X 72 (23.8\%) and urban population $180(59.4 \%)$ were affected more. The association between type of house, crowding status and occurrence of MDR-TB were found statistically significant $(\mathrm{p}<0.05)$ but source of drugs, compliance of treatment, availability of drugs and occurrence of MDR-TB shown statistically highly significant, $(\mathrm{p}<.001)$. Correlation with age, family income and time gap of diagnosis MDR-TB was statistically significant $(\mathrm{p}<0.05)$. Principal Conclusion: Study findings demands establishment of standard diagnostics procedures/laboratories at all secondary and tertiary care hospitals and TB clinics in the country in support of uniformity of intervention therapy.
\end{abstract}

Keywords: Mycobacterium Tuberculosis, Multi drug resistant Tuberculosis, Anti tubercular drugs, Factors related to MDR-TB.

\section{Introduction}

Tuberculosis (TB) is a specific infectious disease caused by Mycobacterium tuberculosis. Tuberculosis continues to be a major public health problem worldwide and now a major threat to world health despite the fact that the causative agent was discovered more than 100 years ago [1] Tuberculosis has affected mankind for over 5000 years, and still continues to be a leading cause of morbidity and mortality, After HIV/AIDS, tuberculosis is the most common cause of

Manuscript received: $20^{\text {th }}$ December 2016

Reviewed: $27^{\text {th }}$ December 2016

Author Corrected: $6^{\text {th }}$ January 2017

Accepted for Publication: $12^{\text {th }}$ January 2017 death and currently the second largest infectious cause of death worldwide. As per World Health Organization (WHO) estimate, in 2012, approximately 8.6 million people developed TB and 1.3 million died from it. About $58 \%$ of these new infections were reported from Asian countries [2,3]. Multi drug resistance tuberculosis (MDR-TB) is caused by bacteria that are resistant to at least two anti-tubercular drugs, isoniazid and rifampicin, two most potent and effective first line antitubercular drugs (ATDs), but not necessarily to other ATDs [4]. Globally, an estimated $3.6 \%$ of new and 
$20.2 \%$ of previously-treated TB cases was diagnosed with MDR-TB in 2012 [5].

MDR-TB does not respond to standard six-month treatment with first-line anti-TB drugs; extended treatment is required involving drugs that are more toxic and more expensive. Cure rate of MDR-TB is 50 to $70 \%$ which is lower than the drug-susceptible TB [6]. Failure to control MDR-TB may lead to another era with TB being regarded as a fatal disease. Despite an overall decreasing incidence and mortality rate for $\mathrm{TB}$, MDR-TB continues to be a serious threat to the current global tuberculosis control effort [7, 8]. Bangladesh is one of the 27 high burden countries for MDR-TB. In Bangladesh, $1.4 \%$ of new tuberculosis patients, and $29 \%$ of previously treated tuberculosis patients are estimated to be MDR-TB. Due to the overall high TB burden in Bangladesh the absolute number of MDR cases is quite large (estimated 1900 for new and 2300 for previously treated patients) [9, 10]. Bangladesh is unique in that it has one of the highest population densities in the world, is one of the high burden countries for TB.

\section{Results}

Results obtained are shown in the tables and graphs in the following headings--

Table- 1: Distribution of respondents by socio-demographic characteristics.

\begin{tabular}{|c|c|c|c|}
\hline Characteristics & Categories & Frequency & Percentage \\
\hline \multirow{7}{*}{ Age in years } & Up to $15 \mathrm{yrs}$ & 9 & 3.0 \\
\hline & 16 to $30 \mathrm{yrs}$ & 184 & 60.7 \\
\hline & 31 to $45 \mathrm{yrs}$ & 48 & 15.8 \\
\hline & 46 to $60 \mathrm{yrs}$ & 50 & 16.5 \\
\hline & $61+\mathrm{yrs}$ & 12 & 4.0 \\
\hline & Total & 303 & 100.0 \\
\hline & \multicolumn{3}{|c|}{ Mean \pm SD $33.09 \pm 14.164$ years } \\
\hline \multirow{3}{*}{ Sex } & Male & 212 & 70.0 \\
\hline & Female & 91 & 30.0 \\
\hline & Total & 303 & 100.0 \\
\hline \multirow{3}{*}{ Religion } & Islam & 286 & 94.4 \\
\hline & Hinduism & 17 & 5.6 \\
\hline & Total & 303 & 100.0 \\
\hline \multirow{3}{*}{ Marital Status } & Married & 219 & 72.3 \\
\hline & Unmarried & 84 & 27.7 \\
\hline & Total & 303 & 100.0 \\
\hline
\end{tabular}

Out of 303 respondents, majority (184) were in the age group of 16 to 30 yrs, comprises $60.7 \%$ and rest of the groups consists of about $40 \%$. The mean age was 33.09 yrs and standard deviation was \pm 14.164 yrs. Sex distribution reveals that maximum $212(70.0 \%)$ were male and only 30.0\% were female. Only $17(5.6 \%)$ were Hindu and majority 219 $(72.3 \%)$ were married.

\section{Materials and Methods}

Descriptive Cross Sectional Study was undertaken to assess the characteristics of MDR-TB patients admitted to IPD and reported to OPD for follow up advice at the National Institute of Diseases of the Chest and Hospital (NIDCH), Mohakhali, Dhaka, was selected purposively for the study place to carry out this research. The duration of the study was 01 year, commencing from 01 Jul 2014 to 30 Jun 2015. The data was collected in the period from 01 Nov 2014 to 30 Mar 2015.

Data was collected, compiled, tabulated and analyzed. The SPSS (Statistical Package for Social Science) programmed, version-20 was used for data analysis.

Verbal and written consent from the respondents were taken during the interview. The respondents were given full assurance on some ethical point of view that, under no circumstances findings of the interview and other information will be disclosed to any unauthorized persons or the authority other than the researcher. 
Table- 2: Distribution of respondents by relationship between type of MDR-TB and Socio-economic factors.

\begin{tabular}{|c|c|c|c|}
\hline \multirow[t]{2}{*}{ Category } & \multicolumn{2}{|c|}{ Type of MDR-TB case } & \multirow[t]{2}{*}{ Test Statistics } \\
\hline & Primary case No $(\%)$ & Acquired case No (\%) & \\
\hline \multicolumn{3}{|c|}{ Location of residence } & \multirow{3}{*}{$\begin{array}{c}\chi^{2} \text { test } \\
(.1 .155, \mathrm{df}=1, \mathrm{p}=.282) \\
\mathrm{p}>0.05\end{array}$} \\
\hline Urban & $30(66.67)$ & $150(58.14)$ & \\
\hline Rural & $15(33.33)$ & $108(41.86)$ & \\
\hline Total & $45(100)$ & $258(100)$ & \\
\hline \multicolumn{3}{|c|}{ Type of house } & \multirow{4}{*}{$\begin{array}{c}\chi^{2} \text { test } \\
(6.172, \mathrm{df}=2, \mathrm{p}=.046) \\
\mathrm{p}<0.05\end{array}$} \\
\hline Kacha & $11(24.44)$ & $114(44.19)$ & \\
\hline Semi-paka & $22(48.89)$ & $92(35.66)$ & \\
\hline Paka & $12(26.67)$ & $52(20.15)$ & \\
\hline Total & $45(100)$ & $258(100)$ & \\
\hline \multicolumn{3}{|c|}{ Crowding status of living area } & \multirow{3}{*}{$\begin{array}{c}\chi^{2} \text { test } \\
(.5 .202, \mathrm{df}=1, \mathrm{p}=.023) \\
\mathrm{p}<0.05\end{array}$} \\
\hline Over crowded & $37(82.23)$ & $224(86.81)$ & \\
\hline Non-overcrowded & $8(17.77)$ & $34(13.19)$ & \\
\hline Total & $45(100)$ & $258(100)$ & \\
\hline
\end{tabular}

The association between type of house and crowding status of living area and occurrence of MDR-TB was statistically significant, $(\mathrm{p}<0.05)$.

Majority $291(96.0 \%)$ were pulmonary case and $12(4.0 \%)$ were extra-pulmonary case. Among the extra-pulmonary cases lymph node MDR-TB was predominant.

Table- 3: Distribution of respondents by time interval between completed TB treatment and diagnosis of MDRTB.

\begin{tabular}{|c|c|c|}
\hline Time interval in year & Frequency & Percentage \\
\hline Up to 01 year & 83 & 32.17 \\
\hline 01 year to 03 years & 74 & 28.68 \\
\hline 03 years to 06 years & 68 & 26.36 \\
\hline 06 years to 09 years & 25 & 9.69 \\
\hline 09 + years & 8 & 3.1 \\
\hline Total & 258 & 100.0 \\
\hline
\end{tabular}

Mean \pm SD 2.7944 \pm 3.91340 yrs Minimum - 02 yrs Maximum- 35 yrs

Distribution of respondents by time interval between completed TB treatment and MDR-TB diagnosis shows that, out of 258 respondents, more than 55\% (55.04\%) were diagnosed with in 01 year to 06 years time and 8 (3.1\%) diagnosed by more than 9 years. The maximum period of interval was 35 years. Mean interval 2.7944 years and SD \pm 3.91340 years.

Table-4.4: Correlation between actual age and actual time interval of diagnosis MDR-TB among respondents

\begin{tabular}{|c|c|c|c|c|}
\hline Category & N & Mean & SD & Test statistics \\
\hline Actual age of respondents & 303 & 33.09 & 14.164 & \multirow{2}{*}{$\begin{array}{c}\text { Pearson Correlation } \\
\text { P }<0.001\end{array}$} \\
\hline $\begin{array}{c}\text { Actual time interval between completed TB } \\
\text { treatment and diagnosis of MDR-TB }\end{array}$ & 258 & 2.7944 & 3.91340 & \\
\hline
\end{tabular}

Correlation shows strongly significant association between age and time interval of diagnosis MDR-TB. [(Pearson Correlation $=0.437, \mathrm{p}=0.000(\mathrm{p}<.001)]$ 
Table-4.5: Correlation between actual family income and actual time interval of diagnosis MDR-TB among respondents.

\begin{tabular}{|c|c|c|c|c|}
\hline Category & N & Mean & SD & Test statistics \\
\hline Actual family income in taka & 303 & 19877.89 & 7647.12 & \multirow{2}{*}{ Pearson Correlation } \\
Actual time interval between completed & 258 & 2.7944 & 3.91340 & P 0.05 \\
TB treatment and diagnosis of MDR-TB & & & & \\
\hline
\end{tabular}

Correlation reveals significant association between family income and time gap of diagnosis MDR-TB. [(Pearson Correlation $=0.125, \mathrm{p}=0.045(\mathrm{p}<.05)]$

\section{Discussion}

This descriptive cross sectional study has been carried out at the National Institute of Diseases of the Chest and Hospital (NIDCH), Mohakhali, Dhaka. Bangladesh, among the MDR-TB patients, those who were already admitted to NIDCH and also reported for follow up. There is a high burden of Multidrug resistant Tuberculosis all over the countries which may be attributed to its demographic and socio-economic profile like poverty, lack of knowledge, attitude and practice, overcrowding, malnutrition, care during illness and lack of social security. Adequate information on prevalence of MDR-TB, epidemiological factors and their interactions are essential prerequisites to redirect health resources in formulating a National Treatment policy which would control the transmission pattern of MDR-TB as well as ensure better patient management and its prevention. As no single factor is fully attributable for emergence of MDR-TB, and study regarding its epidemiology is scarce especially in rural area, we have tried to explore different sociodemographic factors.

In present study we found that, age of majority 184 $(60.7 \%)$ respondents were in the age group of 16 to 30 yrs. The mean age was 33.09 yrs and SD was \pm 14.164 yrs. The association between age and occurrence of MDR-TB was statistically not significant. [FET, 2.043, $\mathrm{p}=.723$, $(\mathrm{p}>.05)]$. Almost similar findings with present study has observed maximum $(63.6 \%)$ were in the age group $\geq 20-40$ years compared with other age groups.

Another study also [12] found, age between 21-30 years covered majority [48 (35.6\%)] and mean age was 30.1 yrs, SD was \pm 13.6 yrs. Similar result were observed in other study. [13]. Malnutrition since childhood leading to weakened immune response, made the younger population more susceptible to MDR-TB in developing countries.
It reveals in this study, maximum $212(70.0 \%)$ were male and only $91(30.0 \%)$ were female. The association between sex and occurrence of MDR-TB showed statistically not significant. $\left[\chi^{2} .785, \mathrm{df}=1, \mathrm{p}=.375\right.$ ( $\mathrm{p}>$ $.05)]$. This findings is exactly similar to the study carried out in Indian population [14] where the majority $1476(70.7 \%)$ were male and only $624(29.3 \%)$ were female. Another study on also observed similar findings [15] where $71.1 \%$ of patients were male and $28.9 \%$ were female. Male populations are vulnerable for MDR-TB as they have more chance to contact with the carriers for their outdoor activities.

In present study, majority $219(72.3 \%)$ were married and $84(27.7 \%)$ were unmarried. The association between marital status and occurrence of MDR-TB had shown statistically not significant. Similar results were found in other studies [16, 17]. In developing countries like Bangladesh most of the poor class families has more family members, so they have economic constrains, malnutrition, poverty, overcrowding, poor hygiene, decreased health care seeking attitude formed a vicious cycle of agent-host- environment. Illiteracy contributed to poor awareness of disease transmission, proper method of sputum disposal and unemployment or poor income decreases health care seeking behavior and proper care during illness, that's why married populations may be affected more. This study witnessed that $291(96.0 \%)$ were pulmonary case and only 12 $(4.0 \%)$ were extra-pulmonary case. Other studies also observed higher number of pulmonary cases [18].

Pulmonary MDR-TB transmitted through airborne routes, so in overcrowded populations the number will be more. In addition malnutrition and overcrowding facilitates ongoing transmission of MDR-TB strains. Longer delays to effective therapy were the most influential factors behind emergence of drug resistance. 
Acquired resistance was found (type of MDR-TB case) in majority $258(85.1 \%)$. Similar findings found in the other study [19] where $88 \%$ of the patients had history of previous anti-TB treatment (acquired case) while the remaining $12 \%$ were new cases (primary case). Another study also [20] observed that 1,776 (11.6\%) and 13,645 $(88.4 \%)$ were new and previously treated patients, respectively. This study strongly highlighted the need of a strengthened continuous surveillance system that monitors the trends of drug resistance over time and places. Drug sensitivity testing is recommended at least for previously treated cases, defaulters, patients who remain smear-positive at the end of the second month of treatment and patients in close contact with MDR-TB cases. The association between crowding status of living area and occurrence of MDR-TB has shown statistically significant. [Chi $=5.202, \mathrm{df}=1, \mathrm{p}=.023(\mathrm{p}<$ .05)]. A cross-sectional, observational study was conducted by Khurram Muhammad, Bushra Khaar, Hamama Tul, Fahim Muhammad et al [21] where found that $22(73.3 \%)$ patients lived in overcrowded residences. Various socio-demographic factors like younger age, illiteracy, unemployment, poverty, overcrowding, lack of cross ventilation at home, improper techniques of sputum disposal thus favoring disease transmission.

\section{Conclusion}

The present study focuses on characteristics of MDRTB patients in a tertiary care hospital of Dhaka city (NIDCH), where standard drug regimen, resistant drugs, drugs used for MDR-TB, types of resistant, site of lesions and the factors related to developed MDR-TB were the variables of the study. The respondents those who were discharged after 02 months of initial hospital treatment, if they were not reported for follow up at regular interval, have the chance of further transmission of disease during the remaining period of drug therapy. Therefore it is needed to develop an intensive follow up network nearest health post at all over the country. Moreover associated disease and co-morbidities condition also demand to follow up and monitor. Study findings also demands establishment of standard diagnostics procedures/laboratories at all secondary and tertiary care hospitals and TB clinics in the country in support of uniformity of intervention therapy in particular. Health education regarding spread of disease, early detection of MDR-TB by strengthened laboratory support, effective therapy, implicating innovative control measures, and applying them would interrupt the ongoing transmission and control this emerging epidemic. Issues such as poverty, malnutrition should be addressed, control of infections and improved hygiene and strong commitment and collaboration among health care providers should become a priority.

\section{Funding: Nil, Conflict of interest: None. Permission of IRB: Yes}

\section{References}

1. Park, k, (2011). Park,s Textbook of Preventive and Social Medicine; "Epidemiology of Communicable Diseases, Tuberculosis", 21st edition, India, Banarsidas Bhanot publisher, 2011, p-159, 162.

2. Zignol M, Dara M, Dean AS, Falzon D et al. Drugresistant tuberculosis in the WHO European Region: An analysis of surveillance data. Drug Resist Update Rev Comment Antimicrob Anticancer Chemother. 2013; 16 (6): 108-15.

3. Menon Sarala, Dharmshale Sujata, Chande Chhaya. Drug resistance profiles of Mycobacterium tuberculosis isolates to first line anti-tubercular drugs: A five years study (2005-2009). J Health Popul Nutr. Feb 2010; 28 (1): 7-13.

4. Gandhi NR, Andrews JR, Brust JC, Montreuil R, Weissman D, Heo M, Moll AP, Friedland GH, Shah NS. Risk factors for mortality among MDR- and XDRTB patients in a high HIV prevalence setting. Int $\mathrm{J}$ Tuberc Lung Dis. 2012 Jan;16(1):90-7. doi: 10.5588/ ijtld.11.0153.

5. Zarir F Udwadia, Gautam Moharil. Multidrugresistant-tuberculosis treatment in the Indian private sector: Results from a tertiary referral private hospital in Mumbai. Web Publication, Department of Pulmonology, Hinduja Hospital and Research Center, Mumbai, Maharashtra, India,Volume:31, Issue:4, Page: 336-341.

6. Gupta A, Nagaraja MR, Kumari P, Singh G, Raman R, Singh SK, Anupurb S. Association of MDR-TB isolates with clinical characteristics of patients from Northern region of India. Indian J Med Microbiol. 2014 Jul-Sep;32(3):270-6. doi: 10.4103/0255-0857.136561.

7. Uzoewulu NG ${ }^{1}$, Ibeh IN, Lawson L, Goyal M, et al. Mycobacterium tuberculosis in Tertiary Hospital South East, Nigeria. Journal of Medical Microbiology \& Diagnosis, 3:141. doi: 10.4172/2161-0703. 1000141, June 29, 2014. 
8. Leung EC, Yew WW, Leung CC, Leung WM, et al. Shorter treatment duration for selected patients with multidrug-resistant tuberculosis. Eur Respir J. 2011;38 (1):227-30.

9. Zaman K, Rahim Z, Yunus M, Arifeen S, Baqui A, Sack D, Hossain S, Banu S, Islam MA, Ahmed J, Breiman R, Black R. Drug resistance of Mycobacterium tuberculosis in selected urban and rural areas in Bangladesh. Scand J Infect Dis. 2005;37(1):21-6.

10. R Israt. A Study on Hematological Indices of Tuberculosis Patients Attending in a Tertiary Care Hospital in Dhaka City. Department of Pharmacy, East West University June, 2012.

11. Maurya AK, Singh AK, Kumar M, Umrao J, Kant S, Nag VL, Kushwaha RA, Dhole TN. Changing patterns and trends of multidrug-resistant tuberculosis at referral centre in Northern India: a 4-year experience. Indian J Med Microbiol. 2013 Jan-Mar;31(1):40-6. doi: 10.4103/0255-0857.108720.

12. Flora MS, Amin MN, Karim MR, Afroz S, Islam S, Alam A, Hossain M. Risk factors of multi-drugresistant tuberculosis in Bangladeshi population: a case control study. Bangladesh Med Res Counc Bull. 2013 Apr; 39(1):34-41.

13. Dr Nirmalya Manna, Kajaree Giri, Dr Malay Mundle et al. Drug resistance pattern, related sociodemographic factors and preventive practices among MDR-TB patients: An experience from a tertiary care setting. IOSR Journal of Dental and Medical Sciences (IOSR-JDMS) Volume 13, Issue 9, Ver. VI (Sep. 2014), PP 16-21.

14. Sethi Sunil, Mewara Abhishek, Kumar Dhatwalia Sunil, et al. Prevalence of multidrug resistance in Mycobacterium tuberculosis isolates from HIV seropositive and seronegative patients with pulmonary tuberculosis in north India. BMC Infectious Diseases 2013,13:137 doi:10.1186/ 1471-2334-13-137, 15 March 2013.
15. Kurniawati Fivy, azhar syed, sulaiman syed, gillani syed wasif et al. Study on drug-resistant tuberculosis and tuberculosis treatment on Patients with drug resistant tuberculosis in chest clinic outpatient Department", International journal of pharmacy and pharmaceutical sciences, vol 4, issue 2, 2012, Issn0975-1491.

16. Jit Bahadur Darnal, Swaddiwudhipong W et al. Multidrug-resistant Tuberculosis Patients in Bhutan", Department of Community and Social Medicine, Mae Sot General Hospital, Tak Province, Thailand August 2011 to July 2012, OSIR, September 2013, Volume 6, Issue 3, p. 6-10 6.

17. Goswami Avranil, Chakraborty Urmita, Mahapatra Tanmay, et al. Correlates of Treatment Outcomes and Drug Resistance among Pulmonary Tuberculosis Patients Attending Tertiary Care Hospitals of Kolkata, India. PLoS ONE 9(10): e109563. doi:10.1371/journal. pone.0109563. October 7, 2014.

18. Helbling Peter, Altpeter Ekkehardt, Egger JeanMarie et al. Treatment outcomes of multidrug-resistant tuberculosis in Switzerland. Swiss Med Wkly. 2014; 144: w14053, 4 December 2014.

19. Banu Sayera, Mujtaba Mahmud Asif, Rahman Toufiq, et. Multidrug-Resistant Tuberculosis in Admitted Patients at a Tertiary Referral Hospital of Bangladesh. PLoS ONE 7(7): e40545.doi: 10.1371/ journal. pone.0040545.

20. Lukoye Deus, Ssengooba Willy, Musisi Kenneth et al. Variation and risk factors of drug resistant tuberculosis in sub-Saharan Africa: a systematic review and meta-analysis". BMC Public Health 2015, 15:291 doi:10.1186/ s12889-015-1614-8.

21. Khurram M, Khaar HT, Fahim M. Multidrugresistant tuberculosis in Rawalpindi, Pakistan. J Infect Dev Ctries. 2012 Jan 12;6(1):29-32.

\section{How to cite this article?}

Mahbubul Hoque AK, Rahman M, Saleh Bhuiyan S.M.M, Rahman M. Characteristics of multi drug resistant tuberculosis cases at a selected tertiary level hospital. Int J Med Res Rev 2017;5(01):68-73. doi:10.17511/ijmrr. 2017.i01.10. 